\title{
The relationship between eosinophilia and slow coronary flow
}

\author{
This article was published in the following Dove Press journal: \\ Therapeutics and Clinical Risk Management \\ 12 August 2015 \\ Number of times this article has been viewed
}

\author{
Yakup Altas,' Ertugrul \\ Kurtoglu, ${ }^{2}$ Baris Yaylak, \\ Erkan Baysal,' Berzal \\ Ucaman,' Hasan Murat \\ Ugurlu,' Mehmet Zülkif \\ Karahan,' Bernas Altintas,' \\ Mehmet Sahin Adiyaman,' \\ İlyas Kaya,' Umut Erdolu,' \\ Kaya Ozen,' Cayan Cakir, ${ }^{3}$ \\ Utkan Sevuk ${ }^{4}$ \\ 'Department of Cardiology, \\ Diyarbakir Gazi Yasargil Education \\ and Research Hospital, ${ }^{2}$ Department \\ of Cardiology, Malatya State Hospital, \\ Malatya, ${ }^{3}$ Department of Cardiology, \\ Memorial Diyarbakir Hospital, \\ ${ }^{4}$ Department of Cardiovascular \\ Surgery, Diyarbakir Gazi Yasargil \\ Education and Research Hospital, \\ Diyarbakir,Turkey
}

\begin{abstract}
Aim: The pathophysiology of slow coronary flow (SCF) involves atherosclerosis, small vessel dysfunction, platelet function disorders, and inflammation. It has been known that eosinophils also play a significant role in inflammation, vasoconstriction, thrombosis, and endothelial dysfunction. We propose to evaluate the relationship between eosinophilia and SCF.

Methods: All patients who underwent coronary angiography between January 2011 and December 2013 were screened retrospectively. Of 6,832 patients, 102 patients with SCF (66 males, mean age $52.2 \pm 11.7$ years) and 77 control subjects with normal coronary angiography (50 males, mean age 50.7 \pm 8.1 years) were detected. Baseline characteristics, hematological test results, and biochemical test results were obtained from the hospital database.

Results: Baseline characteristics of the study groups were comparable between groups. There was no significant difference between groups regarding leukocyte count, paletelet count, and mean platelet volume. However, patients with SCF had a higher eosinophil count than the controls $\left(0.24 \pm 0.17 \times 10^{3} / \mu \mathrm{L}\right.$ vs $\left.0.16 \pm 0.15 \times 10^{3} / \mu \mathrm{L}, P=0.002\right)$. In addition, eosinophil count was found to be correlated with thrombolysis in myocardial infarction (TIMI) frame count in the SCF group $(r=0.3, P<0.01)$. There was no significant correlation between eosinophil count and the number of coronary arteries showing slow flow.

Conclusion: Patients with SCF have higher blood eosinophil count, and this may play an important role in the pathogenesis of SCF. Elevated baseline eosinophil count may indicate the presence of SCF.
\end{abstract}

Keywords: eosinophilia, slow coronary flow, coronary angiography

\section{Introduction}

The pathophysiological mechanisms of slow coronary flow (SCF) remain undetermined. However, several hypotheses have been offered for SCF, comprising a form of early phase of atherosclerosis, small vessel dysfunction, platelet function disorders, and instability between vasoconstrictor and vasodilatory factors. Recently, inflammation has been reported to have an important role in the development of SCF phenomenon. ${ }^{1,2}$

Previous studies have found the incidence of SCF changing between $1 \%$ and $7 \%$ in patients undergoing angiography. ${ }^{3}$ On the other hand, increased cardiovascular mortality associated with SCF has been reported. ${ }^{4}$ It has also been known that eosinophils play an important role in endothelial dysfunction, thrombosis, vasoconstriction, and inflammation. 5,6 Eosinophils stimulate the aggregation and activation of platelets. Furthermore, they relieve the formation of thrombosis through inhibition of thrombomodulin. ${ }^{7-9}$ Therefore, we aimed to evaluate the relationship between blood eosinophil count and SCF as well as its correlation with thrombolysis in myocardial infarction (TIMI) frame count and the number of coronary arteries showing slow flow.
Correspondence: Yakup Altas Department of Cardiology, Diyarbakir Gazi Yasargil Education and Research Hospital, Diyarbakir, 21010, Turkey Tel +90 505 45। 8I08

Email drfrtykp@hotmail.com
Therapeutics and Clinical Risk Management 2015:I I I I87-II9I 


\section{Methods}

\section{Patient selection}

In the present study, angiography records of 6,832 patients who underwent coronary angiography because of chest pain or objective signs of ischemia (treadmill exercise or myocardial perfusion SPECT [single photon emission computed tomography]) between January 2011 and December 2013 were retrospectively evaluated for the presence of SCF. Patients with SCF and who were proved to have normal coronary arteries (NCAs) were included as SCF group. Exclusion criteria were 1) troponin positivity; 2) coronary ectasia on coronary angiogram; 3) moderate-to-severe valvular heart disease; 4) congestive heart failure; 5) chronic renal disease (glomerular filtration rate [GFR] $<60 \mathrm{~mL} / \mathrm{min} / 1.73 \mathrm{~m}^{2}$ ); 6) thyroid dysfunction; 7) anemia; 8) inflammatory disease; 9) active infection; 10) hypertension; 11) hyperlipidemia (low density lipoprotein [LDL] $\geq 160 \mathrm{mg} / \mathrm{dL}$ ); 12) diabetes mellitus; 13) bronchial asthma and chronic obstructive pulmonary disease; 14) drug intake such as steroids and immunosuppressive treatment; 15) current use of cardiovascular medical therapy; 16) under the age of 40; and 17) chronic liver disease.

After applying inclusion and exclusion criteria, a total of 102 patients with SCF were included in the study. Control group comprised 77 patients with angiographically NCAs without SCF.

In addition, patients were further divided into three subgroups: one-vessel, two-vessel, and three-vessel SCF. Routinely measured clinical and laboratory parameters such as complete blood count and biochemical test results were obtained from the medical records of the patients. Venous peripheral blood samples were routinely taken on admission from all patients at hospitalization before coronary angiography. Blood samples were routinely drawn into standardized tubes containing dipotassium ethylenediaminetetraacetic acid (EDTA) and were studied within 2 hours upon arrival in the laboratory. All hematological measurements were performed using an XT-2000i analyzer (Sysmex Corporation of America, Long Grove, IL, USA). Transthoracic echocardiography was performed before coronary angiography with a Philips HD11 XE device using $2.5 \mathrm{MHz}$ phased-array transducer. The left ventricular ejection fraction (LVEF) was assessed by modified Simpson's method. ${ }^{10}$

The present study was approved by the Dicle University ethics committee (Diyarbakir, Turkey) and complies with the requirements of the Declaration of Helsinki.

\section{Coronary angiography}

At our hospital, we perform coronary angiography with Judkin's method. We give a total of 6-8 mL low osmolar contrast agent for each demonstration of right and left coronary arteries. The coronary flow rates were assessed according to the TIMI frame count (TFC) method that was previously standardized. The normal frame counts for the left-anterior descending (LAD) artery (36 \pm 2.3 frames) are 1.7 times greater than the mean for the circumflex $(\mathrm{Cx})$ artery (22.2 \pm 3.8 frames) and the right coronary artery (21.7 \pm 2.8 frames). Therefore, the longer LAD frame counts were corrected by dividing by 1.7 to derive the corrected TFC as described earlier. ${ }^{11}$ The mean TFC for each subject was calculated by summation of the TFCs for the LAD, Cx, and right coronary artery and then dividing the sum by 3 . SCF was defined as corrected TFC $>2$ standard deviations (SDs) from the normal reference values. ${ }^{11}$ Coronary angiograms were independently assessed by two or three cardiologists who were blinded to the clinical findings of the subjects.

\section{Statistical analysis}

SPSS statistical software, version 22.0 (IBM Corporation, Armonk, NY, USA), was used for the statistical analyses. Continuous variables are expressed as mean $\pm \mathrm{SD}$. Categorical variables are expressed as percentages. The normality of distribution of continuous variables was evaluated by the Kolmogorov-Smirnov test. For continuous variables, the Student $t$-test or Mann-Whitney $U$-test was used to test differences between the main groups, and the one-way analysis of variance test or Mann-Whitney $U$-test was used to test differences between the subgroups. Categorical data were analyzed with the $\chi^{2}$ test. Two-tailed $P$-values $<0.05$ were considered as statistically significant. Pearson's or Spearman's correlation was used to determine the strength of the relationship between the parameters when appropriate. Linear regression analysis was used to detect independent factors affecting the presence of SCF.

\section{Results}

All records of 6,832 patients who underwent coronary angiography were retrospectively screened, of which 102 patients

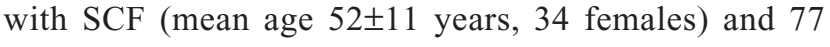
patients with NCAs (mean age $50 \pm 8$ years, 41 females) were detected. There was no statistically significant difference between the two groups with regard to age, sex, body mass index, blood pressures, New York Heart Association classes, LVEF, glucose, tryglicerides, WBC count, platelet count, and neutrophil (Table 1). However, hemoglobin level, and eosinophil count were found to be elevated in patients with SCF when compared to those with NCA $(14.8 \pm 3.4 \mathrm{~g} / \mathrm{L}$ vs $13.8 \pm 1.7 \mathrm{~g} / \mathrm{L}, P=0.03 ; 0.24 \pm 0.17 \times 10^{3} / \mu \mathrm{L}$ vs $0.16 \pm 0.15 \times 10^{3} /$ $\mu \mathrm{L}, P=0.002$, respectively) (Table 1 ). Eosinophil count was 
Table I Baseline and laboratory characteristics of the study groups

\begin{tabular}{llll}
\hline Variables & $\begin{array}{l}\text { SCF group } \\
(\mathbf{n}=1 \text { 02) }\end{array}$ & $\begin{array}{l}\text { Control } \\
\text { group }(\mathbf{n}=\mathbf{7 7})\end{array}$ & $\begin{array}{l}\text { P-value } \\
\end{array}$ \\
\hline Age (years) & $52.2 \pm 11.7$ & $50.7 \pm 8.1$ & 0.3 \\
Male sex, $\mathrm{n}(\%)$ & $66(66.1)$ & $36(35.9)$ & 0.5 \\
BMI, $\mathrm{kg} / \mathrm{m}^{2}$ & $22.7 \pm 1.8$ & $22.9 \pm 1.9$ & 0.4 \\
Smoking, $\mathrm{n}(\%)$ & $70(68.6)$ & $50(64.9)$ & 0.6 \\
Systolic blood pressure, $\mathrm{mmHg}$ & $118.4 \pm 9.8$ & $117.7 \pm 10.3$ & 0.6 \\
Diastolic blood pressure, $\mathrm{mmHg}$ & $75.1 \pm 6.6$ & $75.3 \pm 7.6$ & 0.8 \\
NYHA class & $1.03 \pm 0.19$ & $1.03 \pm 0.19$ & 0.9 \\
LVEF, \% & $59.4 \pm 2.7$ & $59.5 \pm 2.7$ & 0.9 \\
Glucose, mg/dL & $94.8 \pm 12.8$ & $93.77 \pm 14.3$ & 0.5 \\
Triglycerides, $\mathrm{mg} / \mathrm{dL}$ & $154 \pm 68$ & $151 \pm 53$ & 0.7 \\
WBC count, $\times 10^{3} / \mu \mathrm{L}$ & $8.1 \pm 2.1$ & $7.8 \pm 1.7$ & 0.3 \\
Hemoglobin, $\mathrm{g} / \mathrm{dL}$ & $14.8 \pm 3.4$ & $13.8 \pm 1.7$ & 0.03 \\
Platelet count, $\times 10^{3} / \mu \mathrm{L}$ & $237.0 \pm 56.1$ & $243.4 \pm 66.4$ & 0.5 \\
Neutrophil, $\times 10^{3} / \mu \mathrm{L}$ & $4.8 \pm 1.6$ & $4.7 \pm 1.2$ & 0.6 \\
Eosinophil count, $\times 10^{3} / \mu \mathrm{L}$ & $0.24 \pm 0.17$ & $0.16 \pm 0.15$ & 0.002
\end{tabular}

Abbreviations: BMI, body mass index; LDL, low density lipoprotein; LVEF, left ventricular ejection fraction; NYHA, New York Heart Association; SCF, slow coronary flow; WBC, white blood cell.

not significantly different among patients with one-vessel, two-vessel, and three-vessel SCF (Table 2). Eosinophil count was mildly correlated with TFC in patients with SCF ( $r=0.3, P=0.002$; Figure 1). Regression analysis showed that eosinophil count was an independent factor for the presence of SCF (Table 3).

\section{Discussion}

In our study, we have found significant differences in eosinophil count between patients with SCF and those with NCAs. The higher eosinophil count may indicate the presence of SCF.

The pathophysiology of SCF is not fully understood. However, it has a close relationship with accompanying atherosclerosis, oxidative stress, endothelial dysfunction, increased inflammatory parameters, vasculitis, and platelet function disorder. ${ }^{1,2,5,6}$ Especially, the association between SCF and inflammatory parameters is intriguing. Recent studies showed that SCF was associated with various inflammatory markers such as serum YKL 40, hs-CRP, plasma factors IX and XII, myeloperoxidase levels, soluble serum CD 40

Table 2 Eosinophil counts in SCF subgroups

\begin{tabular}{lll}
\hline Subgroup & $\mathbf{n}$ & $\begin{array}{l}\text { Eosinophil } \\
\text { count, } \times 10^{3} / \mu \mathbf{L}\end{array}$ \\
\hline One vessel & 46 & $0.22 \pm 0.17$ \\
Two vessels & 28 & $0.25 \pm 0.17$ \\
Three vessels & 28 & $0.24 \pm 0.17$ \\
\hline
\end{tabular}

Abbreviation: SCF, slow coronary flow.

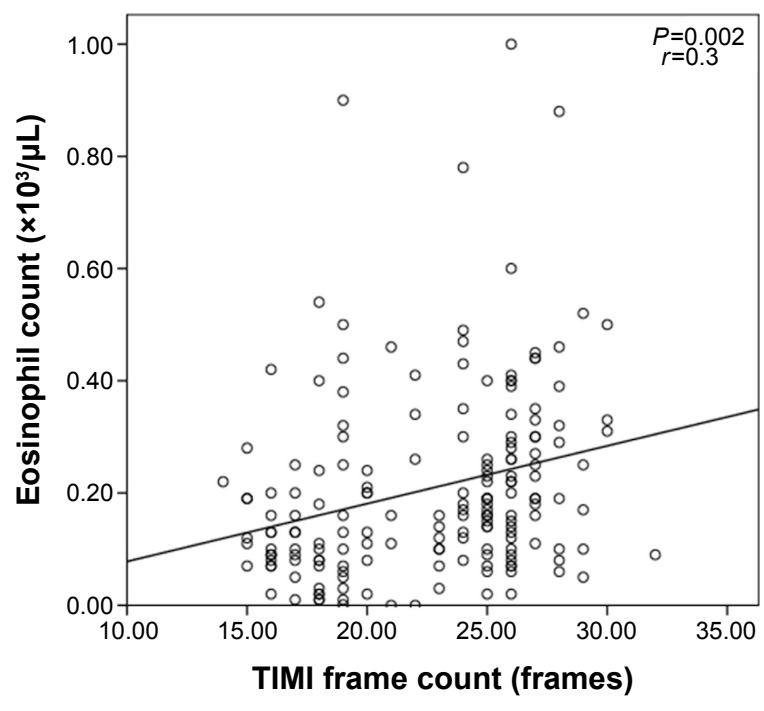

Figure I The correlation between eosinophil count and TIMI frame count. Abbreviation: TIMI, thrombolysis in myocardial infarction.

ligand, interlukein 6 (IL-6), intercellular adhesion molecule 1 (ICAM-1), WCAM-1, and E-selectin. ${ }^{12-17}$ Eosinophils are laden with a variety of granule-associated molecules that play a role in the formation of thrombosis and vascular damage. Two of the four principal cationic proteins of the eosinophil granule, major basic protein and eosinophil peroxidase, were shown to be platelet agonists. ${ }^{7}$

Eosinophils create an increased disposition to thrombosis by way of leukocyte, platelet stimulation, and release of tissue factor., ${ }^{7}$ Eosinophils store and release tissue factors and proteins like major basic protein and eosinophil peroxidase. These proteins have important role in activating platelets and thrombus formation by inhibiting trombomodulin. Activated eosinophils and eosinophil granule proteins were detected within the necrotic and thrombotic lesions and, furthermore, were found mainly in acute tissue damage in the endocardium and in the walls of small blood vessels. These findings indicated the potential role of eosinophils in vascular injury and inflammation. ${ }^{19-21}$ There is some evidence that eosinophil granule proteins can activate factor XII, platelets, and mononuclear cells in patients with hypereosinophilic syndrome, which may also underlie the procoagulant activity of

Table 3 Regression analysis with SCF as the dependent variable

\begin{tabular}{lll}
\hline Variable & $\beta$ & $P$-value \\
\hline Age & -0.03 & 0.69 \\
White blood cells & 0.005 & 0.95 \\
Platelets & 0.07 & 0.33 \\
Hemoglobin & -0.13 & 0.07 \\
Neutrophils & -0.01 & 0.91 \\
Eosinophils & -0.21 & 0.008 \\
\hline
\end{tabular}

Abbreviation: SCF, slow coronary flow. 
eosinophils. ${ }^{7}$ Recent studies have shown that eosinophils are related to arterial tortuosity, dilatation, thrombosis, cardiac syndrome $\mathrm{X}$, and nondipper hypertension. ${ }^{22,23}$ Additionally, eosinophils have been shown to be associated with stent thrombosis, stent restenosis, coronary artery calcification, and acute coronary syndromes as described earlier. Furthermore, it was reported that elevated serum eosinophil concentration might be responsible for cardiac mural thrombus and embolic events. ${ }^{24-27}$

In our study, we demonstrated an increased eosinophil count in SCF patients when compared to the control subjects with NCAs. However, we did not observe a significant association between eosinophil count and the number of affected vessels, which have SCF. In addition, compatible with previous studies, we found a significantly higher level of hemoglobin in the SCF group. But it has not reached a statistical power in regression analysis. It has been well known that hematocrit value has been shown to be a significant determinant of blood viscosity in many studies. ${ }^{28-30}$ Mares et al evaluated the role of the blood viscosity in patients with ischemic heart disease and found that high viscosity is an independent predictor of both in-hospital and long-term adverse outcomes. ${ }^{31}$ Blood viscosity is also a risk factor in cardiovascular events. $^{32}$

Our study has some limitations. First, due to the retrospective design of our study, risk factor modification could not be completely made. Second, since NCA definition was based on the angiographic appearance, all atherosclerotic plaques could not be excluded. Third, retrospective studies may inherently carry a selection bias.

\section{Conclusion}

In conclusion, our findings may contribute to the etiopathogenesis of SCF. Further randomized studies are needed to confirm our results.

\section{Disclosure}

The authors report no conflicts of interest in this work.

\section{References}

1. Li JJ, Xu B, Li ZC, Qian J, Wei BQ. Is slow coronary flow associated with inflammation? Med Hypotheses. 2006;66:504-508.

2. Gokce M, Kaplan S, Tekelioglu Y, Erdogan T, Kucukosmanoglu M. Platelet function disorder in patients with coronary slow flow. Clin Cardiol. 2005;28:145-148.

3. Goel PK, Gupta SK, Agarwal A, Kapoor A. Slow coronary flow: a distinct angiographic subgroup in syndrome X. Angiology. 2001;52: 507-514.

4. Amasyali B, Turhan H, Kose S, et al. Aborted sudden cardiac death in a 20-year-old man with slow coronary flow. Int J Cardiol. 2006;109: $427-429$.
5. Sasano H, Virmani R, Patterson RH, Robinowitz M, Guccion JG. Eosinophilic products lead to myocardial damage. Hum Pathol. 1989;20(9): $850-857$.

6. Wang J, Mahmud SA, Thompson JA, Geng JG, Key NS, Slungaard A. The principal eosinophil peroxidase product. $\mathrm{HOSCN}$ is a uniquely potent phagocyte oxidant inducer of endothelial cell tissue factor activity: a potential mechanism for thrombosis in eosinophilic inflammatory states. Blood. 2006;107(2):558-565.

7. Rohrbach MS, Wheatley CL, Slifman NR, Gleich GJ. Activation of platelets by eosinophil granule proteins. J Exp Med. 1990;172(4): $1271-1274$.

8. Olsen EG, Spry CJ. Relation between eosinophils and endomyocardial disease. Prog Cardiovasc Dis. 1985;27(4):241-254.

9. Blétry O, Solal P, Herreman G, et al. Cardiac manifestations of the hypereosinophilia syndrome: a report on fifteen cases. Ann Med Interne (Paris). 1981;132(1):16-25.

10. Lang RM, Bierig M, Devereux RB, et al; Chamber Quantification Writing Group; American Society of Echocardiography's Guidelines and Standards Committee; European Association of Echocardiography. Recommendations for chamber quantification: a report from the American Society of Echocardiography's Guidelines and Standards Committee and the Chamber Quantification Writing Group, developed in conjunction with the European Association of Echocardiography, a branch of the European Society of Cardiology. J Am Soc Echocardiogr. 2005; 18:1440-1463.

11. Gibson CM, Cannon CP, Daley WL, et al. TIMI frame count: a quantitative method of assessing coronary artery flow. Circulation. 1996;93: 879-888.

12. Xu Y, Meng HL, Su YM, et al. Serum YKL-40 is increased in patients with slow coronary flow. Coron Artery Dis. 2015;26(2):121-125.

13. Yurtdaş M, Yaylali YT, Kaya Y, Ozdemir M. Increased plasma highsensitivity C-reactive protein and myeloperoxidase levels may predict ischemia during myocardial perfusion imaging in slow coronary flow. Arch Med Res. 2014;45(1):63-69.

14. Türkmen M, Toprak C, Açar G, et al. Plasma factor XI and XII activity in patients with slow coronary flow. Blood Coagul Fibrinolysis. 2014.

15. Durakoğlugil ME, Kocaman SA, Çetin M, et al. Increased circulating soluble CD40 levels in patients with slow coronary flow phenomenon: an observational study. Anadolu Kardiyol Derg. 2013;13(1):39-44.

16. Li JJ, Qin XW, Li ZC, et al. Increased plasma C-reactive protein and interleukin-6 concentrations in patients with slow coronary flow. Clin Chim Acta. 2007;385:43-47.

17. Turhan H, Saydam GS, Erbay AR, et al. Increased plasma soluble adhesion molecules; ICAM-1, VCAM-1, and E-selectin levels in patients with slow coronary flow. Int J Cardiol. 2006;108(2):224-230.

18. Moosbauer C, Morgenstern E, Cuvelier SL, et al. Eosinophils area major intravascular location for tissue factor storage and exposure. Blood. 2007;109(3):995-1002.

19. Slungaard A, Vercellotti GM, Tran T, Gleich GJ, Key NS. Eosinophil cationic granule proteins impair thrombomodulin function. A potential mechanism for thromboembolism in hypereosinophilic heart disease. J Clin Invest. 1993;91(4):1721-1730.

20. Yoshikawa S, Kayes SG, Parker JC. Eosinophils increase lung microvascular permeability via the peroxidasehydrogen peroxide-halide system. Bronchoconstriction and vasoconstriction unaffected by eosinophil peroxidase inhibition. Am Rev Respir Dis. 1993;147(4):914-920.

21. Rodeghiero F, Castaman G, Ruggeri M, Cazzavillan M, Ferracin G, Dini E. Fibrinolytic studies in 13 unrelated families with factor XII deficiency. Haematologica. 1991;76(1):28-32.

22. Kuzeytemiz M, Demir M, Senturk M. The relationship between eosinophil and nondipper hypertension. Cor Vasa. 2013;55(6):487-491.

23. Demir M, Sentürk M, Kuzeytemiz M. The relationship between eosinophil and cardiac syndrome X. Clin Appl Thromb Hemost. 2013;21(4): $325-328$.

24. Niccoli G, Schiavino D, Belloni F, et al. Preintervention eosinophil cationic protein serum levels predict clinical outcomes following implantation of drug-eluting stents. Eur Heart J. 2009;30(11):1340-1347. 
25. Joner M, Finn AV, Farb A, et al. Pathology of drug-eluting stents in humans: delayed healing and late thrombotic risk. J Am Coll Cardiol. 2006;48(1):193-202.

26. Yutani C, Ishibashi-Ueda H, Suzuki T, Kojima A. Histologic evidence of foreign body granulation tissue and de novo lesions in patients with coronary stent restenosis. Cardiology. 1999;92(3):171-177.

27. Tanaka M, Fukui M, Tomiyasu K, et al. Eosinophil count is positively correlated with coronary artery calcification. Hypertens Res. 2012; 35(3):325-328.

28. Chien S. Shear dependence of effective cell volume as a determinant of blood viscosity. Science. 1970;168:977-978.
29. Baskurt OK, Meiselman HJ. Blood rheology and hemodynamics. Semin Thromb Hemost. 2003;29:435-450.

30. Cokelet GR, Goldsmith HL. Decreased hydrodynamic resistance in the two-phase flow of blood through small vertical tubes at low flow rates. Circ Res. 1991;68:1-17.

31. Mares M, Bertolo C, Terribile V, Girolami A. Hemorheological study in patients with coronary artery disease. Cardiology. 1991;78:111-116.

32. Fornal M, Korbut RA, Krolczyk J, Grodzicki T. Left ventricular geometry and rheological properties of erythrocytes in patients at cardiovascular disease risk. Clin Hemorheol Microcirc. 2009;43:203-208.

\section{Publish your work in this journal}

Therapeutics and Clinical Risk Management is an international, peerreviewed journal of clinical therapeutics and risk management, focusing on concise rapid reporting of clinical studies in all therapeutic areas outcomes, safety, and programs for the effective, safe, and sustained use of medicines. This journal is indexed on PubMed Central, CAS,
EMBase, Scopus and the Elsevier Bibliographic databases. The manuscript management system is completely online and includes a very quick and fair peer-review system, which is all easy to use. Visit http://www.dovepress.com/testimonials.php to read real quotes from published authors.

Submit your manuscript here: http://www.dovepress.com/therapeutics-and-clinical-risk-management-journal 